\author{
Military Technical College \\ Kobry El-Kobbah, \\ Cairo, Egypt.
}

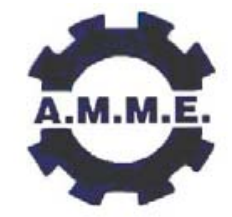

\author{
$13^{\text {th }}$ International Conference \\ on Applied Mechanics and \\ Mechanical Engineering.
}

\title{
AIRCRAFT PROPULSION SYSTEMS : A DIESEL HYBRID ENGINE
}

\author{
FRANCIA ${ }^{*}$ D. and PIANCASTELLI ${ }^{* *}$ L.
}

\begin{abstract}
Recent developments in diesel piston engine technology have increased performance in a very significant way. In this paper a new hybrid diesel-turbine engine is introduced and it is compared to up-to-date turboprops. The weak point of the common rail engine is the difficulty to obtain very fast injectors for large engines. Automotive injectors are available only for small power outputs. The problem was solved with a dual chambers piston with two injectors per cylinder. It is then possible to use off-the-shelf automotive common rail components even on very large diesel engines with benefits on combustion especially at medium low power level. The other more interesting advantage is a significant increase on crankshaft maximum speed and reduction of head mechanical stress. It is then possible to have smaller and more powerful turbodiesel and hybrid engines. Another advantage is the improved reliability of a dual injection system. The diesel - turbine hybrid power unit proposed in this paper combines the advantages of the turboprop/turbofan/turboshaft and piston turbo-dieselprop / turbo-diesel-fan / turbodiesel engines. However, It should be clear than the automotive commercial common rail components should be treated to use jp4, jp8 and jet(A1) fuels and to fulfil aeronautical requirements.
\end{abstract}

\section{KEY WORDS}

Diesel, turbo-compound, combustion chamber, engine.

* Graduate student, Dpt. of Mechanical Engineering, Bologna University, Forlì, Italy.

** Professor, Dpt. of Mechanical Engineering, Bologna University, Forli, Italy. 


\section{INTRODUCTION}

When in 1945 the large piston engines of WWII were abandoned, the turbines were sleek engines with very low pressure ratio, huge fuel consumption and limited offdesign performances. Now turbines have grown up to huge pressure ratio with more and more axial stages, increased weight, reduced fuel consumption and still limited offdesign performance. Large petrol piston engines were replaced by turbodiesel engine. Several generations of turbodiesel engines were installed on cars and the recent common rail developments put the diesel performances well ahead spark ignition engines.

Last generation of automotive common rail diesel have very flat torque and efficiency curves with speeds that may exceed $7000 \mathrm{rpm}$. The result is lighter, smaller, very efficient and more powerful engines. In the automotive field the enemy of diesel are soot emissions.

However, SCR (Selective Catalytic Reduction) solves many of pollution problems without affecting the performances of large diesel engines. In the $4000 \mathrm{HP}$ field the performances of common rail diesel overcome turbine performances, with optimal offdesign performance and reduced weights. Huge fuel savings are obtainable without performance reduction.

In this paper a new concept of large turbodiesel common rail engine with twin combustion chambers is introduced. This solution makes it possible to use the highly optimized and developed off-the-shelf automotive common rail injection system even on large engine. This solution improves combustion at low and medium loads and makes it possible to obtain high speed diesel engine. Special, optimized combustion chamber and valve ducts are necessary for optimal tuning. The result of this research project is a new concept of large diesel engine for airplanes, trucks, heavy duty vehicles and energy production. For aircrafts a turbodiesel version was designed for executive turbofan airplanes, while an hybrid solution was optimized for the C130j airplane class.

\section{THE HYBRID PROPULSION}

An hybrid engine was designed to achieve the advantages of both the turboprop and the turbodiesel engines. This solution is optimal for the aeronautical requirements of reliability, high power and long times between overhaul. The hybrid engine is composed of a diesel engine and a turbine similar to the Allison 250 C17 [1-3].

Two versions of diesel engine are proposed: the VD007 is a V12 common rail engine, displacement of $20,500 \mathrm{cc}$, capable of $6,000 \mathrm{rpm}$ and the VD716, V16 common rail engine, displacement of $27,340 \mathrm{cc}$, capable of $6,000 \mathrm{rpm}$. These data were extrapolated from tests on different turbodiesel common rail engines, with similar thermal charge or with similar combustion chamber. The output power for the two propellers, that are contra rotating, is obtained both from diesel and from the turboshaft through two separated speed reducers.

In cruise configuration the turbine works as turbocharger of the diesel engine with minimum fuel consumption, Fig.1. In addition, the turboshaft combustion chamber is bypassed so the compressor output is directed to the piston engine. The wastegate 
valve is not necessary because the engine inlet pressure is always the maximum obtainable from the turbine.

During the take-off the exhaust gas of the diesel engine are heated from $1,000 \mathrm{~K}$ (about $750^{\circ} \mathrm{C}$ ) to $1,700 \mathrm{~K}$ (about $1,450^{\circ} \mathrm{C}$ ) by the turbine burner and the available power of the hybrid unit is almost doubled, Fig.2.

In the case of the VD007 12V 21-litre hybrid engine, the maximum output power is increased from 2,300 HP to 3,500 HP. In the case of the VD716 16V 27-litre hybrid engine, the maximum output power is increased from $3,000 \mathrm{HP}$ to $4,730 \mathrm{HP}$. In case of complete failure of the piston engine, the turbine can stand alone; in this condition the turboshaft power still output 1,300 HP (1,730 HP for the VD716), Fig.3.

The VD007 piston has the exclusive configuration of two combustion chambers on the top, Fig.4. The twin injection system needs two injectors for cylinder, two rails to reach pressures up to 1500 bar, two high pressure and two low pressure pumps. This system guarantees high reliability thanks to the components redundancy.

Some failures related to single injection system could be overcome by the twin system and these are: common rail or high pressure pipes failure, single or multiple injector failure, high or low pressure pumps failure.

The two combustion chambers configuration makes it possible to use commercial automotive injectors even in large displacement engines [4-5]. At the intermediate power levels, the combustion efficiency is improved by optimal injection nozzle size. No stress or wear problems are given by single chamber use at intermediate power levels. For this purpose the two combustion chambers have been positioned along the piston pin axis. The dual chamber system guarantees also improved reliability due to dual separate common rail systems [6-7].

The head, the crankcase and the crankshaft have been designed to satisfy the following requirements:

\section{VD007}

$>$ Direct injection - common rail - V12 @ 55 diesel engine;

Displacement 20,500 cc;

$>$ Power 2,300 HP;

> Maximum rotational speed $5,600 \mathrm{rpm}(6,000 \mathrm{rpm}$ possible)

$>$ The torque $(3,000 \mathrm{Nm})$ curve is flat and maximum from $1,700 \mathrm{rpm}$ to $5,000 \mathrm{rpm}$;

$>$ Maximum combustion chamber pressure 160 bar (design limit 190 bar);

$>$ Fuels jp4, jp8, jet A1, diesel.

\section{VD716}

D Direct injection - common rail - V16 @ 55 diesel engine;

$>$ Displacement $27,340 \mathrm{cc}$;

$>$ Power 3,000 HP;

> Maximum rotational speed $5,600 \mathrm{rpm}(6,000 \mathrm{rpm}$ possible)

$>$ The torque $(4,000 \mathrm{Nm})$ curve is flat and maximum from $1,700 \mathrm{rpm}$ to $5,000 \mathrm{rpm}$;

$>$ Maximum combustion chamber pressure 160 bar (design limit 190 bar);

$>$ Fuels jp4, jp8, jet A1, diesel. 
It has been experimentally and analytically demonstrated that as the inlet pressure increases, from 3.25 bar up to 6.2 bar (max pressure ratio of turbine), the peak combustion pressure does not increase of a proportional amount. It is then unnecessary to install a wastegate valve.

An experimental method has been tested in order to determine the maximum power obtainable from an aircraft diesel engine [8]. An experimental session was necessary to estimate the real values of pressure and thermal loads on the piston and head. The simple and original method described herein made it possible to define the two constants for the description of the off-design behaviour of the diesel engine. The maximum resultant pressure on the piston and the head was evaluated starting from two contributing factors:

- The contributing factor of compression

- The contributing factor of combustion

These contributing factors were examined and quantified separately [9].

It was assumed that the compression phase follows a polytrophic law, while the combustion phase follows an exponential law. It is then possible to estimate the maximum obtainable power or, if the maximum power is known, it is possible to evaluate the maximum combustion chamber pressure. If many experimental data are available for the same engine it is possible to evaluate the performance envelope of the engine. This was demonstrated for the 1900 jtd avio engine and the other diesel engines tested at the Forli University laboratories. For similar engines the same coefficients can be used with confidence, since they are linked to the combustion chamber geometry and to the crankshaft speed. In the case of the VD007 the single combustion chamber is similar to the 1900 jtd at top performance and the rotational speed is in the same range. The estimated correlation between maximum combustion pressure $(Z)$ with the air inlet pressure $(Y)$ and geometric pressure ratio $(X)$ is shown, Fig. 5. This graph was obtained with the above described method [15].

In order to optimize the VD007 engine installation also the Meredith-effect cooling system has been designed, Fig.6, [10]. Meredith effect's additional thrust may reach as much as $2,000 \mathrm{~N}$. This assumption is based on several experimental data from tests performed during and after WWII [11-13].

\section{RESULTS}

The weak point of the turboshaft engines is the specific fuel consumption usually above $270 \mathrm{gr} / \mathrm{kWh}$ (195 gr/HPh). Diesel hybrid engines, fuelled by jet fuels, have better efficiency (180 gr/kWh-130 gr/HPh). They can develop power up to 5,000 HP (take off) with less powerplant weight and less fuel.

The diesel engines proposed in this paper are designed specifically for aircraft propulsion and the hybrid solution introduces the diesel advantages in many different fields.

The hybrid VD007 gives to the C130j the same performance of the original turboprops with fuel savings of at least $30 \%$. The APU (Auxiliary Power Unit) can be spared since diesel efficiency is very high even at very low power output. From 1,700 rpm to 5,000 $\mathrm{rpm}$ the output torque is constant and at the maximum level obtainable. It is then 
possible to implement flying speed strategies that further reduce fuel consumption as aircraft weight diminishes during flight. Loitering and taxiing consumption are extremely low and proportional to the current power output.

TBO is $3,000 \mathrm{~h}$ due to the reduced power output. Design limit of VD007 is about 2,900 HP. If necessary, instantaneous extra-torque can be obtained to overcome difficult flying condition, obstacles or extremely short runway.

A significant improvement in C130J performance can be obtained with the VD716 engine. In this case, however, structural reinforcement are needed. Performances of these hybrid systems are detailed, Tab. 1-2, and the VD007 and the VD716 installation on the $\mathrm{C} 130 \mathrm{~J}$ is proposed, its structural limits permitting, Fig 7-8. The performances of the diesel part in the hybrid system could be compared to the MTU 883 diesel engine ones, Fig. 9, [16].

The 6 cylinder version of the VD007 can be used on executive aircraft of the Cessna Citation X class. In this case the two engines are housed in the fuselage and are linked to the fans through two independent transmissions and speed reducers. Also in this case huge fuel savings can be achieved.

The VD007 family is articulated into six different engines, the differences are both technical and market-oriented: VD007 turbocharged for traction/maritime, VD007 turbocharged for main battle tanks, VD007 turbo-compound cogeneration, natural gas/H2 VD007 turbo-compound, VD007 hybrid/turbo aerospace engine and VD716 hybrid aerospace engine.

\section{CONCLUSIONS}

Recent development of diesel piston engines can improve the basic requirements of low emissions, reliability and low fuel consumption when compared to the up-to-date turboprop and turbofans. It is feasible to build an aircraft engine for the C130j, ATR 72 and 42 and the Dornier 328 . The VD007 and the VD716 give the possibility to reduce fuel consumption and to obtain emergency power only from turboshaft, to reach weights and sizes comparable to turboprops.

The turbocharged version can be used on executive aircraft of the Citation X class. However a lot of work is still to be made to reach the remarkable reliability, serviceability and durability standards of turbofan and turboprops. Diesel engines are more complicated than turboshafts and reliability will suffer accordingly especially in the first period. Particular care is to be given to FADEC (Full Authority Digital Electronic Control) design, since automotive electronic control units are inadequate from the reliability point of view and ill conceived for aeronautical use [14].

Turbomatching is relatively easy for the VD007 hybrid system This type of engine runs from $75 \%$ to $100 \%$.. The original turboshaft is conceived for helicopter use and it is quite "flexible" with excellent off-design performance. Should stall/surge problems arise during the transition phase it is also possible to use the turbine burner. In any case the original turboshaft has been modified with different blade shape for the centrifugal compressor that are optimized for off-design use. The same engines, in the turbocharged version, can be used in other application fields. 


\section{REFERENCES}

[1] Ministero dell'Aviazione, Motore DB 605 AC di costruzione FIAT, FIAT, Pub. Tecniche Motori Aviazione, (1943) (in italian).

[2] Mercedes Benz Flugmotor, DB605, Anleitungen fuer kontrolle, mech. Bearbeitung und montage, bei besonders wichtigen operationen. Pruefstand, Nov., (1941) (in German).

[3] AN-02-55AC-3, Overhaul instructions for aircraft engines models V1650-3, -7 and Merlin 68, 69, (1944).

[4] Glassey S.F., Stockner A.R., Flinn M.A., HEUI-A New Direction for Diesel Engine Fuel Systems, Mar 1-5 1993, SAE Paper 930270.

[5] Stockner A.R., Flinn M.A., Camplin F.A., Development of the HEUI Fuel System Integration of Design, Simulation, Test, and Manufacturing, Mar 1-5 1993, SAE Paper 930271.

[6] Uchida N., Shimokawa K., Kudo Y., Shimoda M., Combustion Optimization by Means of Common Rail Injection System for Heavy-duty Diesel Engines, SAE paper 982679.

[7] Yamaki Y., Kamikubo H., Kohketsu S., Mori K., Kato T., Application of Common Rail, Fuel Injection System to a Heavy-duty Diesel Engine, SAE paper 942294.

[8] Fulton B., Leviticus L., Variable Injection Timing Effects on the Performance and emission of A Direct Engine, SAE paper 932385.

[9] El-Mahallawy F., El-Din Habik S., Fundamentas and Technology of Combustion, Elsevier, (2002), ISBN: 0-08-044106-8.

[10] Piancastelli L., Pellegrini M., The bonus of aircraft piston engines, an update of the Meredith effect, International Journal of Heat and Technology, n. 25, pp. 51-56 (2007)

[11] Hoerner S.F., Fluid Dynamic Drag, Hoerner, (1965).

[12] Kuchemann D., Weber J., Aerodynamics of propulsion, Mc Graw-Hill, (1953).

[13] Kays W.M., London A.L., Compact Heat Exchanger, Mc Graw-Hill, (1955).

[14] Richeson D. A., Amann R. W., The Electronically Controlled 6.5L Diesel Engine, SAE paper 932983.

[15] Francia D., Piancastelli L., An innovative method for determining maximum power obtainable from common rail turbocharged diesel engine starting from experimental data, AMME 13th International Conference, May 27-29 2008 , Cairo, Egypt, to be published.

[16] Developing science and technologies list, Department of Defense, August 2003 
TABLES

Table 1

\begin{tabular}{|c|c|}
\hline \multicolumn{2}{|c|}{ The VD007 performances } \\
\hline Turboprop Take Off Power & $1350 \mathrm{HP}$ \\
\hline Output rpm & $6000 \mathrm{rpm}$ \\
\hline \multicolumn{2}{|l|}{ Output rpm } \\
\hline Max Output Power & 2300 HP@0 $\rightarrow 5000 m$ \\
\hline \multicolumn{2}{|l|}{ Max Output Power@ 5000rpm } \\
\hline \multicolumn{2}{|l|}{ Hybrid Engine (turbine+diesel) } \\
\hline Max Take Off Power & $3650 \mathrm{HP}$ \\
\hline Cruise Power & $2300 \mathrm{HP} @ 0 \rightarrow 5000 \mathrm{~m}$ \\
\hline $\begin{array}{l}\text { Radiator Additional Thrust } \\
\text { (cruise) }\end{array}$ & $2600 \mathrm{~N}$ \\
\hline Propellers (\# 2 contra rotating) & $1450 \mathrm{rpm}$ \\
\hline Cruise Thrust & $38000 \mathrm{~N} @ 0 \rightarrow 5000 \mathrm{~m}$ \\
\hline Max Take Off Thrust & $56000 \mathrm{~N}$ \\
\hline
\end{tabular}

Table 2

\begin{tabular}{|c|c|}
\hline \multicolumn{2}{|c|}{ The VD716 performances } \\
\hline Turboprop Take Off Power & $1750 \mathrm{HP}$ \\
\hline Output rpm & $6000 \mathrm{rpm}$ \\
\hline Output rpm & V16 Diesel Engine \\
\hline Max Output Power & $2980 \mathrm{HP} @ 0 \rightarrow 5000 \mathrm{~m}$ \\
\hline \multicolumn{2}{|l|}{ Max Output Power@5600 rpm } \\
\hline \multicolumn{2}{|l|}{ Hybrid Engine (turbine+diesel) } \\
\hline Max Take Off Power & $4730 \mathrm{HP}$ \\
\hline Cruise Power & $2980 \mathrm{HP} @ 0 \rightarrow 5000 \mathrm{~m}$ \\
\hline $\begin{array}{l}\text { Radiator Additional Thrust } \\
\text { (cruise) }\end{array}$ & $2600 \mathrm{~N}$ \\
\hline Propellers (\# 2 contra rotating) & $1450 \mathrm{rpm}$ \\
\hline Cruise Thrust & $51000 \mathrm{~N} @ 0 \rightarrow 5000 \mathrm{~m}$ \\
\hline Max Take Off Thrust & $76600 \mathrm{~N}$ \\
\hline
\end{tabular}




\section{FIGURES}

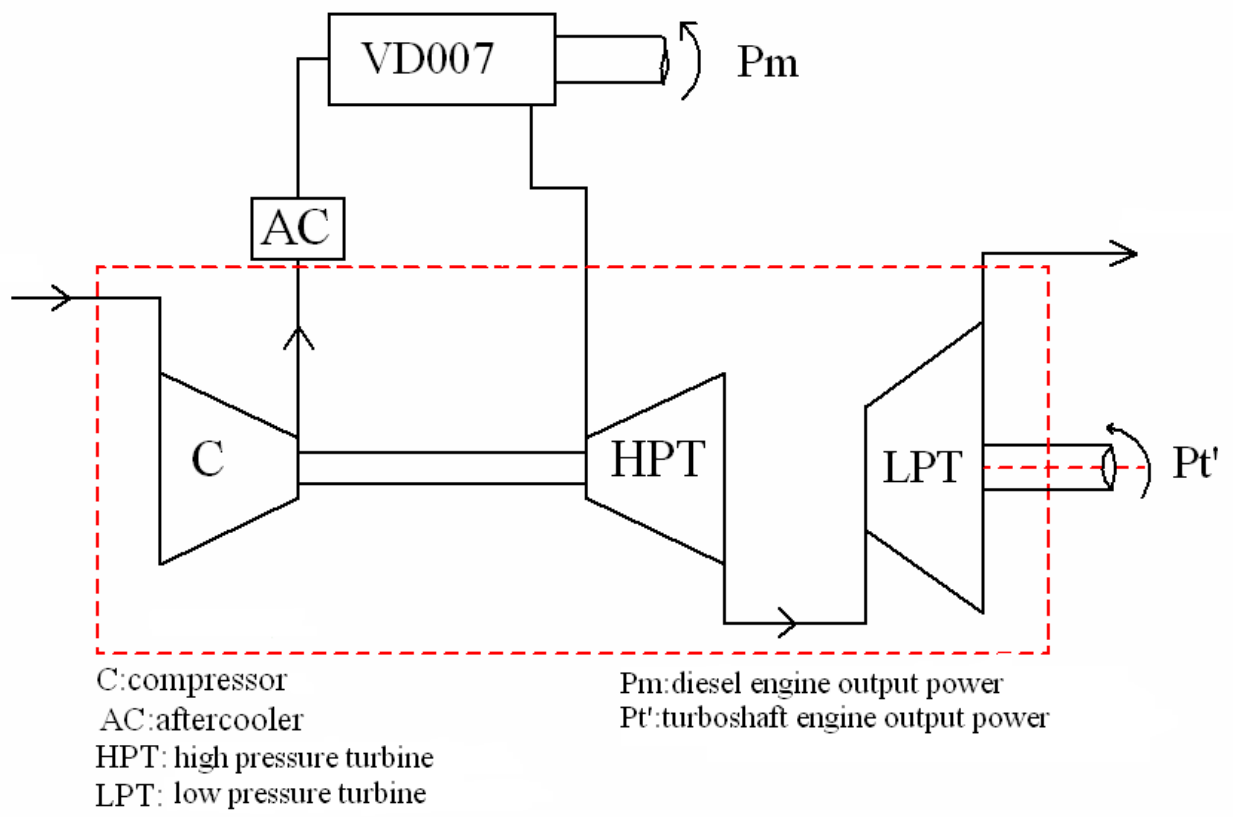

Fig.1. Cruise configuration

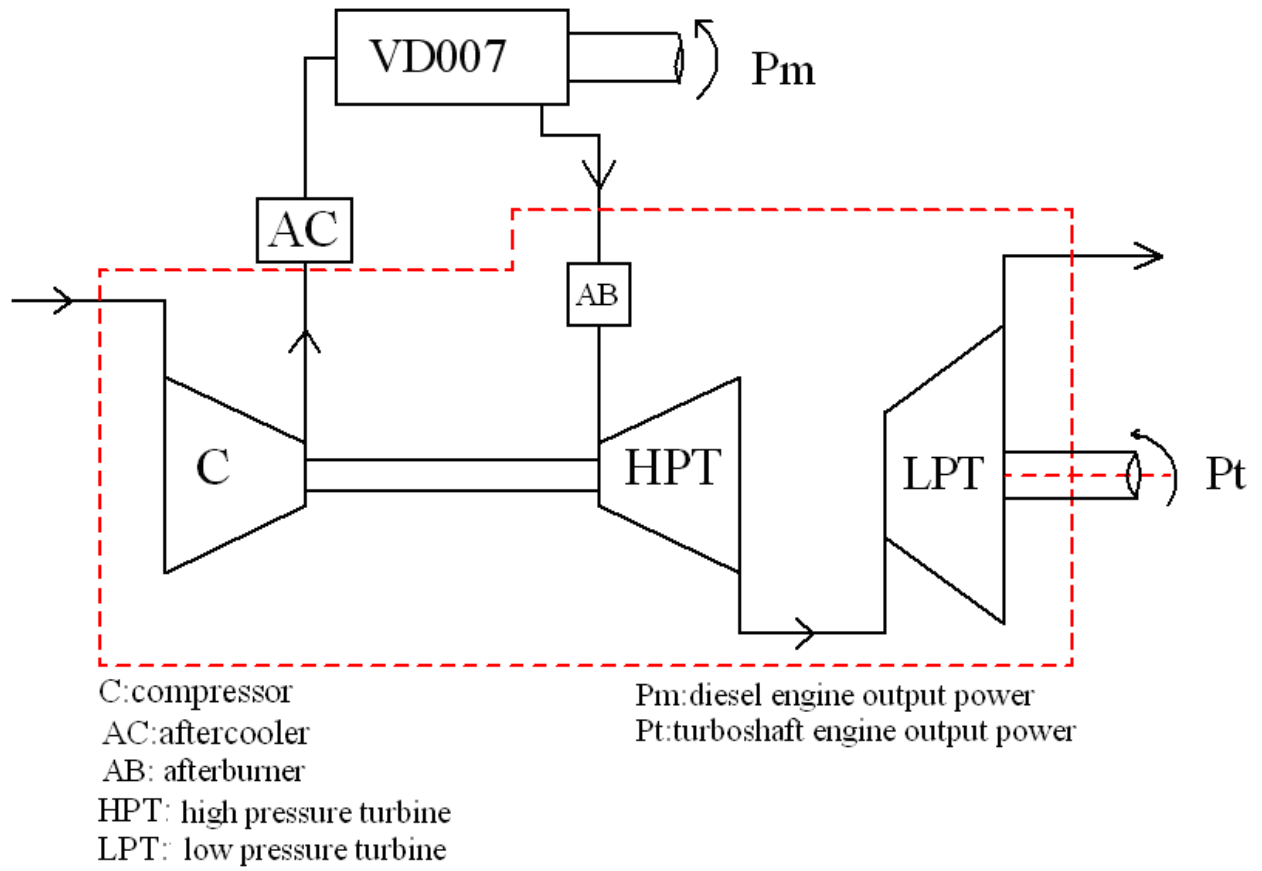

Fig.2. Take off configuration 


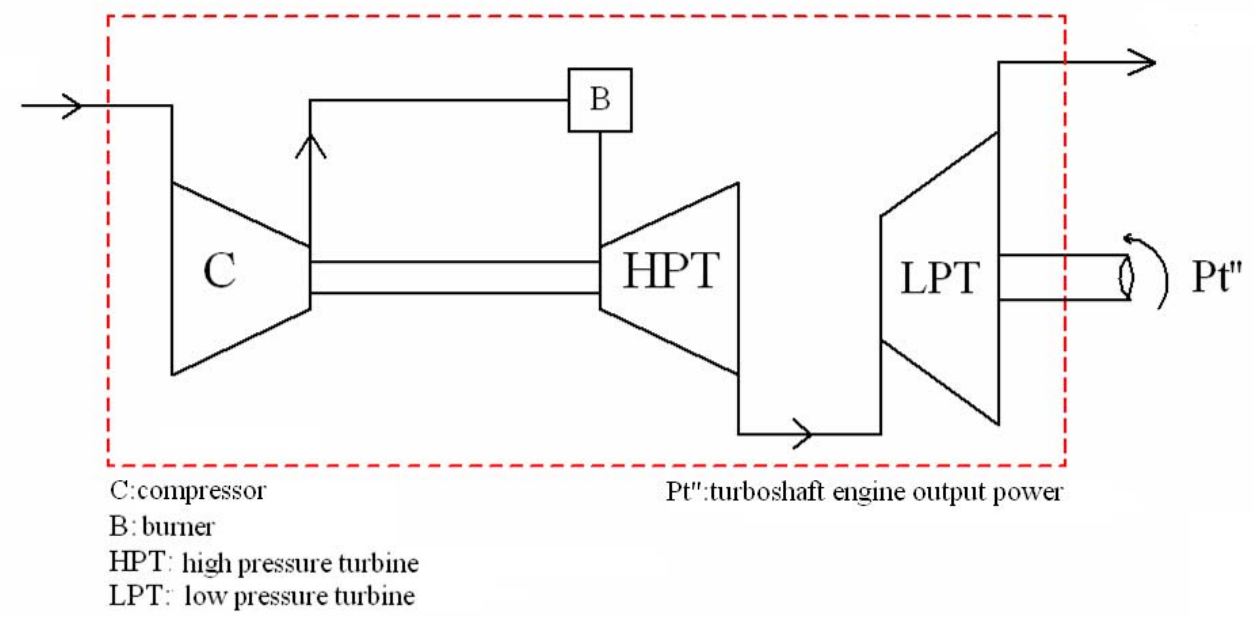

Fig.3. Emergency configuration (Turboshaft only)

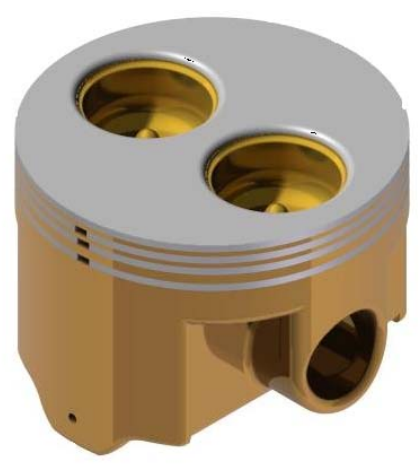

Fig.4. The twin combustion chamber piston

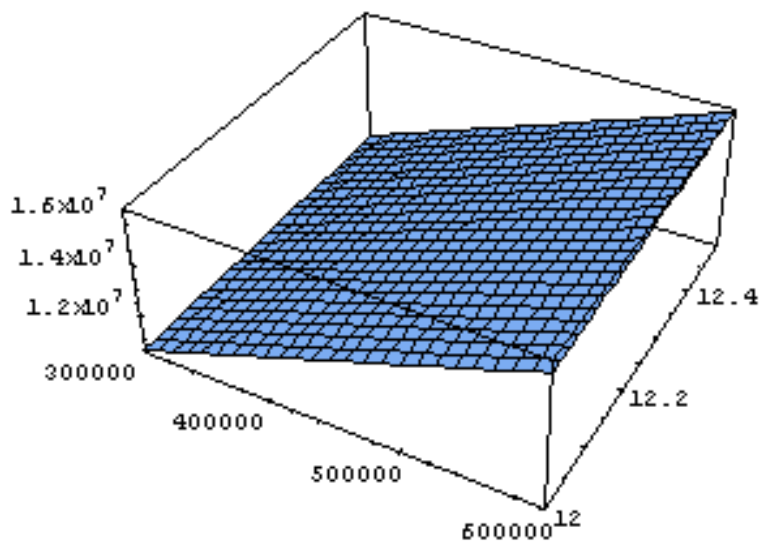

Fig.5. The correlation between maximum combustion pressure (Z-Pa) with the air inlet pressure ( $\mathrm{Y}-\mathrm{Pa})$ and geometric pressure ratio ( $\mathrm{X}$ non dimensional). 


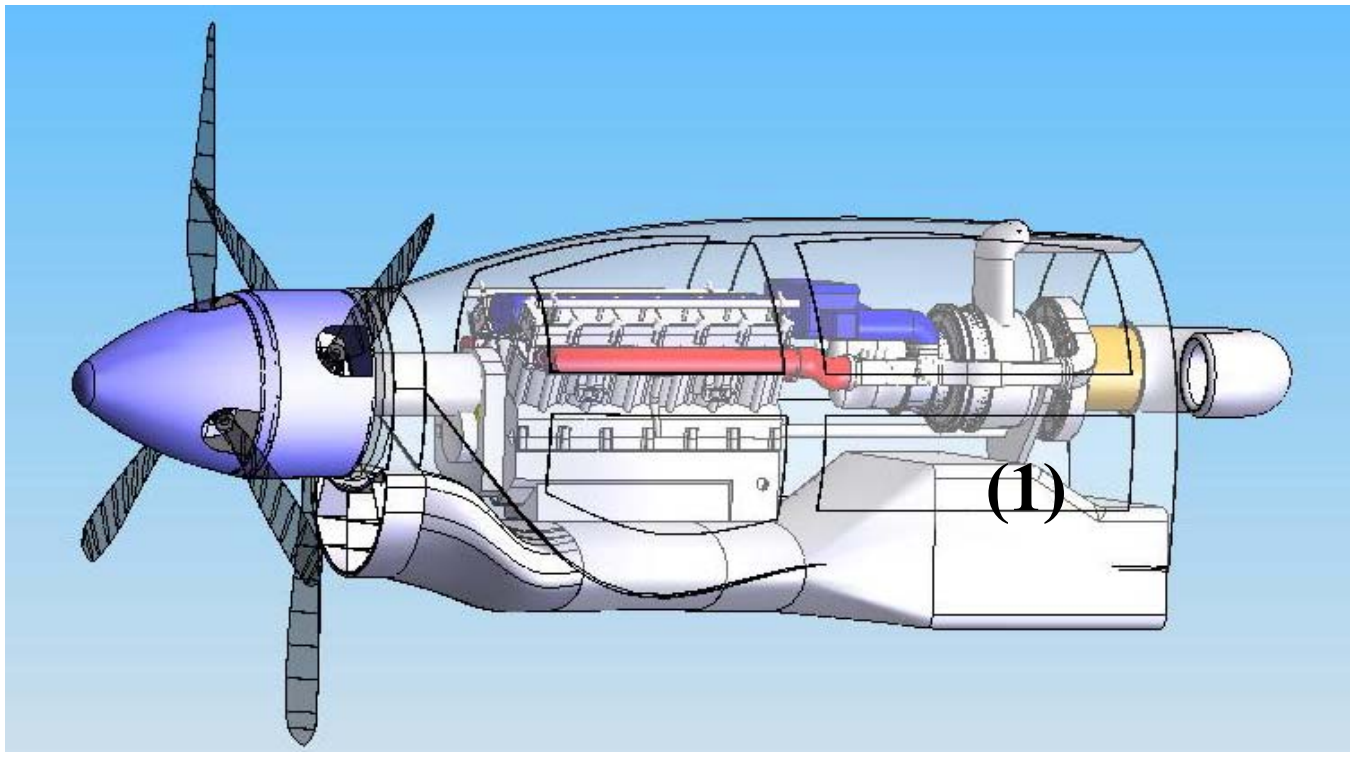

Fig.6: VD007 on C130j, (1) is the Meredith's effect cooling system

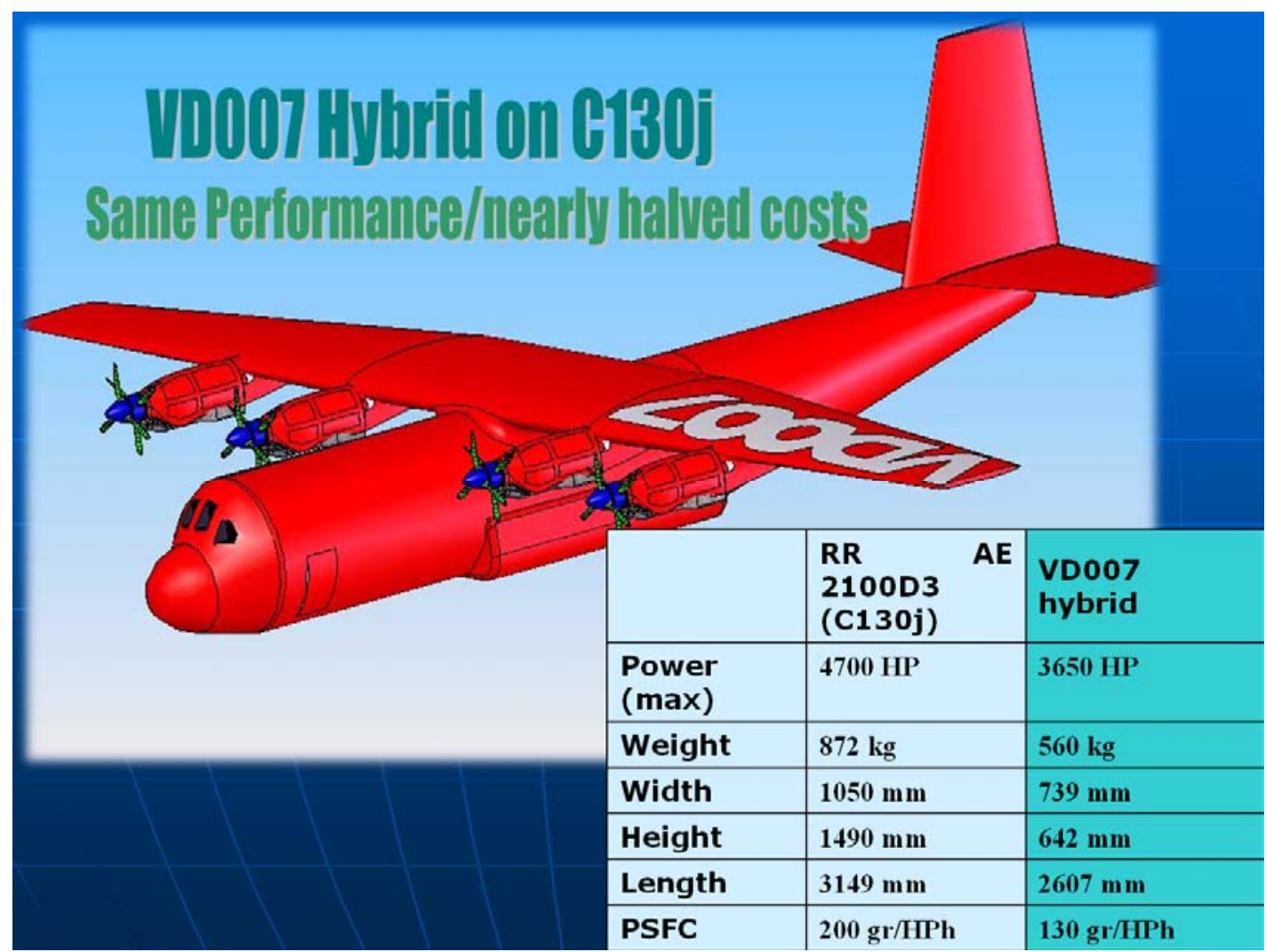

Fig.7: VD007 on C130J 




Fig.8: VD716 on C130J.

\begin{tabular}{|l|l|l|l|l|}
\hline & $\begin{array}{l}\text { Mt883- } \\
1500\end{array}$ & $\begin{array}{l}\text { MT883- } \\
\mathbf{2 2 5 0}\end{array}$ & VD007 & VD00716 \\
\hline Power HP & $\mathbf{1 , 5 0 0}$ & $\mathbf{2 , 2 5 0}$ & $\mathbf{2 , 3 0 0 ( * )}$ & $\mathbf{2 , 9 0 0}$ \\
\hline Max rpm & $\mathbf{3 , 0 0 0}$ & $\mathbf{3 , 0 0 0}$ & $\mathbf{5 , 6 0 0}$ & $\mathbf{5 , 6 0 0}$ \\
\hline Displacement cc & $\mathbf{2 7 , 4 0 0}$ & $\mathbf{2 7 , 4 0 0}$ & $\mathbf{2 0 , 5 0 0}$ & $\mathbf{2 7 , 3 0 0}$ \\
\hline Compression ratio & $\mathbf{1 4 . 5}$ & $\mathbf{1 4 . 5}$ & $\mathbf{1 2 . 5}$ & $\mathbf{1 2 . 5}$ \\
\hline Pme bar & $\mathbf{1 6 . 4 2}$ & $\mathbf{2 4 . 6 3}$ & $\mathbf{1 6 . 8}$ & $\mathbf{1 6 . 8}$ \\
\hline Turbo boost bar & $\mathbf{3 . 5}$ & $\mathbf{5 . 4}$ & $\mathbf{3 . 2 5}$ & $\mathbf{3 . 2 1}$ \\
\hline Size (LxWXH) mm & $\mathbf{1 , 7 0 0 x 9 6 4}$ & $\mathbf{1 , 7 0 0 \times 9 6 4}$ & $\mathbf{1 , 2 0 0 \times 7 0 0}$ & $\mathbf{1 , 6 0 0 \times 7 0 0}$ \\
& x965 & x965 & x642 & x642 \\
\hline Mass kg & $\mathbf{1 , 8 0 0}$ & $\mathbf{1 , 8 0 0}$ & $\mathbf{5 0 0}$ & $\mathbf{6 0 0}$ \\
\hline DEVELOPMENT & Serial & Design & Design & Design \\
& Production & Finished & Finished & Finished \\
\hline
\end{tabular}

(*) possible emergency power 2,500 HP for 1 minute

Fig.9: Diesel engine comparison 